\title{
Introduction to the Jubilee issue in Endocrine Pathology
}

\author{
Virginia LiVolsi • Anne Marie McNicol
}

Published online: 21 February 2014

(C) Springer Science+Business Media New York 2014

Endocrine Pathology is 25 years old! In celebration of this anniversary, the editors, editorial board, and the publisher have solicited articles from leading endocrine pathologists in various aspects of the endocrine system. These articles review the developments and accomplishments within endocrine pathology over the past quarter century.

Introductory articles on the history of the Journal and its sponsoring organization, the Endocrine Pathology Society, are provided by doctors Kovacs and Asa and DeLellis. Following these are reviews covering pituitary, thyroid (follicular as well as $\mathrm{C}$ cell lesions), parathyroid, ovary, gastrointestinal endocrine cells, pancreatic islets, and adrenal (both cortex and medulla). We are please to also include articles on alterations in adipose tissue and their relationship to glucose metabolism.

The articles cover aspects of endocrine pathology known 25 years ago and trace the exciting developments in the understanding of pathophysiology and molecular alterations in the major endocrine glands. In all of pathology over the past quarter century, only the knowledge explosion in hematopathology can compare to that seen in endocrinology and metabolism. Our expert authors have, in many cases, been at the forefront and in the research laboratories that have been responsible for the acquisition of this new knowledge.

We present this issue to the readership of the Journal with the hope that they will recognize the important contributions that have been made in this field and the value that these have given to clinical medicine and the care of patients.

We anticipate that at the Golden Jubillee of the Journal, the knowledge in this field will have quadrupled and that our understanding of molecular biology, proteomics, metabolomics, nanotechnology, and explorations in fields as yet unknown will enhance developments in research and clinical techniques to help patients in the future.

Virginia A. LiVolsi, MD

Anne Marie McNicol, MD

\footnotetext{
V. LiVolsi $(\triangle)$

Hospital of the University of Pennsylvania, 3400 Spruce St., Philadelphia, PA 19104, USA

e-mail: linus@mail.med.upenn.edu

A. M. McNicol $(\square)$

Molecular and Cellular Pathology, UQ Centre for Clinical Research,

The Royal Brisbane and Women's Hospital, University of

Queensland, Level 6 Building 71/918, Herston, 4029 Brisbane,

QLD, Australia

e-mail: a.mcnicol@uq.edu.au
} 